\title{
William Carstairs Reid, M.Inst.C.E.
}

Mr William Carstairs Reid, M.Inst.C.E., died on October 29, 1937. At the time of his death he was Senior Partner of Messrs J. \& A. Leslie \& Reid, C.E., which firm for nearly one hundred years has been responsible for the construction of many important engineering works in Scotland, chiefly in connection with Water Supplies.

$\mathrm{Mr}$ Reid's grandfather, the late Mr James Leslie, acted as Engineer for the Edinburgh Water Company, and in that capacity constructed the North Pentland Reservoirs. Mr Reid's father, the late Mr Robert Carstairs Reid, as a partner in the firm, took a leading part in the design and construction of the Moorfoot Scheme, which involved the construction of four large reservoirs.

Mr William Carstairs Reid attended Engineering Classes at the University of Edinburgh, and after an office training acted as Resident Engineer on the construction of Talla Water Works, the largest of the schemes for supplying water to Edinburgh. Mr Reid was assumed as a partner in the firm in 1905, shortly after the completion of the Talla Works. He was associated with the Edinburgh Water Undertaking for nearly forty years, and for over twenty-five years represented his firm in acting as Engineer of the Edinburgh Water Undertaking. This period saw great expansion of the city, and many important extensions of the Water Works were carried out under Mr Reid's direction involving an expenditure of nearly one million pounds.

$\mathrm{Mr}$ Reid was frequently consulted by other Water Authorities throughout Scotland and was also called upon to act as arbiter in many important cases. He had an extensive knowledge of Waterworks Administration and Law, and in the consolidation of the Edinburgh Water Acts into the Edinburgh Corporation Order 1924 he assisted the town very extensively in compiling this Order.

While Mr Reid was a partner, the firm of Messrs Leslie \& Reid carried out many Water Schemes, of which those in connection with the Kirkcaldy District of Fife, Bathgate District of West Lothian, and Stirlingshire and Falkirk were the most important and involved expenditure of over $€ \mathrm{I}, 200,000$.

$\mathrm{Mr}$ Reid was unmarried. He was much liked by a large circle of friends and employees with whom he came in contact. His principal recreations were fishing and golf.

He was elected a Fellow of this Society in 1924.

P. B. G. 